\title{
Incidence of Eosinophilia in Rural Population in North India: A Study at Tertiary Care Hospital
}

\author{
Rimpi Bansal, Anureet Kaur, Anil K Suri, Puneet Kaur, Monika Bansal and Rupinderjeet Kaur \\ Dept. of Pathology, Gian Sagar Medical College and Hospital, Banur, Dist Patiala, Punjab. India
}

\section{ABSTRACT}

Background: Eosinophilia is abnormally high number of eosinophils in the blood. Normally, eosinophils constitute 1 to $6 \%$ of the peripheral blood leukocytes, at a count of 350 to 650 per cubic millimeter. Eosinophilia can be categorized as mild (less than 1500 eosinophils per cubic millimeter), moderate (1500 to 5000 per cubic millimeter), or severe (more than 5000 per cubic millimeter). Eosinophilia may be primary or secondary. The aim of the study was to determine the incidence of eosinophilia and evaluate the patients thoroughly for the cause of eosinophilia.

Method: The study was conducted in the Pathology department in the medical college and hospital in rural are of Punjab. Complete blood count and peripheral blood film study was done in almost all the patients visiting the hospital. The patients with eosinophilia were segregated and were made to fill the detailed proforma. The information included family history, chief complaints, food habits, disease history and drug history. A thorough general examination and diagnostic work up followed.

Result: In all $3442(10.7 \%)$ patients visiting the hospital had eosinophilia; out of this 2136 (62\%) patients had mild eosinophilia, 1297 $(37.7 \%)$ had moderate and $9(0.3 \%)$ had severe eosinophilia. 2451(71.2\%) patients were males and $991(28.8 \%)$ were females. Age group of patients varied from 3 yrs to 74 yrs. The chief complaints of our patients were related to fever, cough, rashes, breathlessness, wheezing etc. other major group of patients had symptoms of abdominal pain, diarrhea, pallor, pica and loss of appetite.

Conclusion: Eosinophilia appears to be a common occurrence in the in the rural population around our hospital. The most common etiologies were due to parasitic, protozoal or fungal infestations and infections. Allergy related problem also constituted a significant health problem in the local population.

Keywords: Eosinophilia, Allergy, Atopy, Punjab

\section{Introduction}

Eosinophis are type of blood cells whose number varies from 350- 650/ cubic microliter. Any abnormality in eosinophil count is usually detected on a complete blood count (CBC). Alternatively, the eosinophil count may be recorded as a percentage of total white blood cell (leukocyte) count, along with other white blood cells like monocytes, basophils, neturophils or lymphocytes. Eosinophils are present in bone marrow and other tissues in the body and their proportion can be assessed by studying the biopsy of the respective tissue. Any value above the normal range is known as eosinophilia.

\section{Materials and Methods:}

This is a prospective study beginning from February 2010. It was done in a medical college located in rural area of North India. A total number of 32217 patients visited our hospital from February 2010 to February 2011. This includes outpatients, inpatients and emergency ward patients. Complete blood count is the basic test done in the patients. In our laboratory, this was done on Sysmex XT1800i hematology analyser. Peripheral blood film were prepared in all samples received for $\mathrm{CBC}$. The slides were stained using Leishman stain. Manual differential count was done on all smears. Out of the total number of samples received, 3442 patients were found to have eosinophilia. The patients were evaluated in order to determine the cause of eosinophilia.

Patients with hematological malignancy were excluded from our study. The stepwise approach included-

a. Degree of Eosinophilia: Estimate absolute eosinophil count

b. History: Chief complaints and their duration

- Record of previous eosinophil counts and Medical History; detailed patient history with emphasis on disorders know to be associated with eosinophilia including allergic/atopic disease.

- Medication History- make a detailed list of all medications (including nutritional supplements, vitamins, herbal preparations)

- Origin: Whether the patient is native to this place or Migrant from regions where particular eosinophilia-associated infections may be common 
- Occupational History: Review occupational exposures

- Dietary History: Review carefully; query dietary indiscretions, nutritional supplements

- Family History: Review whether others in family have eosinophilia suggesting a common exposure or familial nature of disease

c. Physical Examination: for chest and per abdomen findings , skin lesion, soft tissues masses and lymphadenopathy.

d. Initial Laboratory Evaluation included studies to assess organ function (liver function tests, renal function tests, urinalysis, chest radiograph), inflammation (CRP/ESR),

e. Further Diagnostic Evaluations like biopsies, fluid, CT and MRI to define focal lesions, bone marrow aspirates and biopsies and other serological tests wherever required.

\section{Results}

Total number of patients registered for OPD was 33217. EDTA sample were received for hemogram/ CBC. Peripheral blood film was prepared and stained with Leishman stain. In all $3442(10.7 \%)$ patients had eosinophilia; decade wise distribution is shown in Table 1. Table-2 shows distribution of patients according to severity of eosinophilia. $2136(62 \%)$ patients had mild eosinophilia, 1297(37.7\%) had moderate and $9(0.3 \%)$ had severe eosinophilia. 2451(71.2\%) patients were males and 991(28.8\%) were females. Age group of patients varied from 3 yrs to $74 \mathrm{yrs}$. Highest incidence was seen in patients in second decade of life in males whereas in females it was seen in age group between 30 to 50 years. Table- 3 depicts the distribution of various patients according to the probable etiology of eosinophilia. Hematoloigal examination was done in all the patients, nasal endoscopy in 87 patients, stool examination in 45 patients, skin biopsy in 14 , lymph node biopsy in four, gastrointestinal biopsy in 29 and liver biopsy in two patients. The chief complaints of our patients were related to fever, cough, rashes, breathlessness, wheezing etc. Other major group of patients had symptoms of abdominal pain, diarrhea, pallor, pica and loss of appetite. Specific diagnosis of intestinal helminthiasis like hookworm (Ancyclostome duodenale), tapeworm (Cestodes), hydatid cyst (Ecchinococcus granulosus), filariasis (Wucheria bancrofti) could be made in 28 patients, with the help of tissue biopsy. Two patients of roundworm infestation had history of purging out worms during sleep and pain in abdomen. A significant proportion of patients (148) came with complains of nasal stuffiness, post nasal drip and recurrent attack of cold. These patients were operated for nasal mass which on histopathological examination were inflammatory polyp (89), allergic polyp(13), fungal polyp (31) and sinonasal polyp(05). Some patients (46) of eosinophilia presented with complaints of dyspepsia, reflux, nausea, pain in abdomen or diarrhea. Definite histopathological diagnosis was available in 13 cases; chronic gastritis (04), chronic duodenitits (01), celiac disease (03), chronic colitis (02), ulcerative colitis(02) and Crohn's disease (01). History of drug ingestion was found in five patients. Four patients were diagnosed with Hodgkins lymphoma on lymphnode biopsy and eosinophilia on peripheral blood examination. Ten patients were known case of malignancy ; six patients had serous adenocarcinoma of ovary, two patients had squamous cell carcinoma of lung and two patients had invasive ductal carcinoma of breast. A definite diagnosis could not be achieved in significant proportion patients. Severe eosinophilia was noted in patients of roundworm infestation $(n=2)$, and allergy $(n=3)$. In four patients who presented with persistent severe eosinophilia, all known etiologies were ruled out and were hence diagnosed as case of hypereosinophilic syndrome. All the patients showed down trending of absolute eosinophil count when trated with diethylcarbamazine (hetrazan).

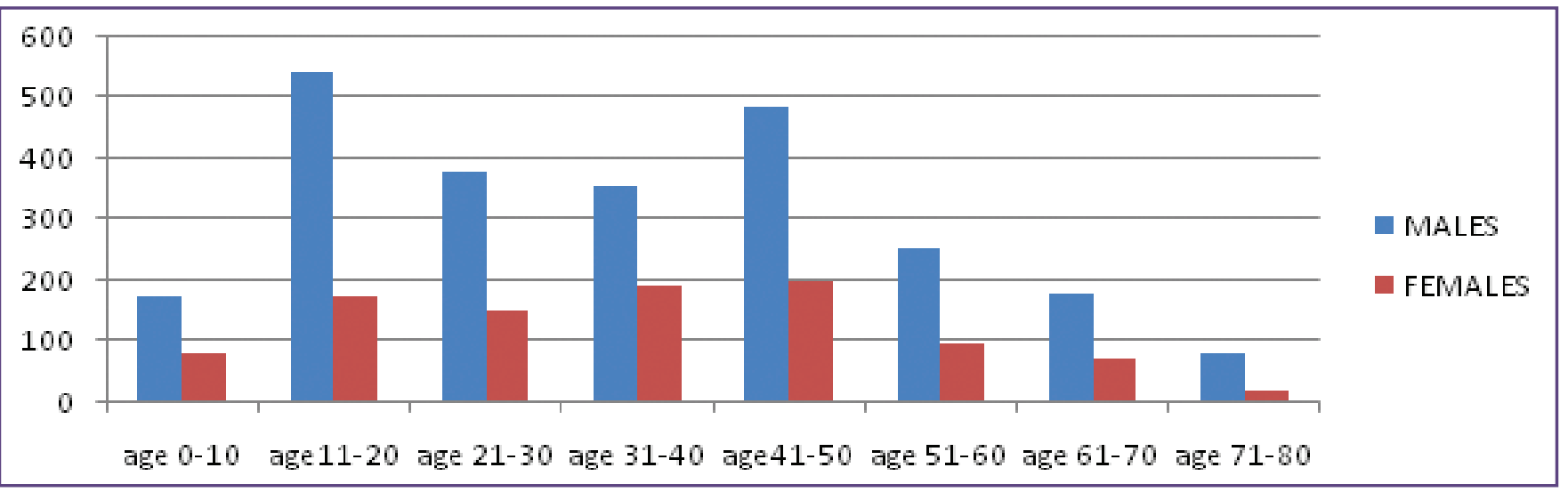

Graph 1: Age and sex wise distribution of patients with eosinophilia. 


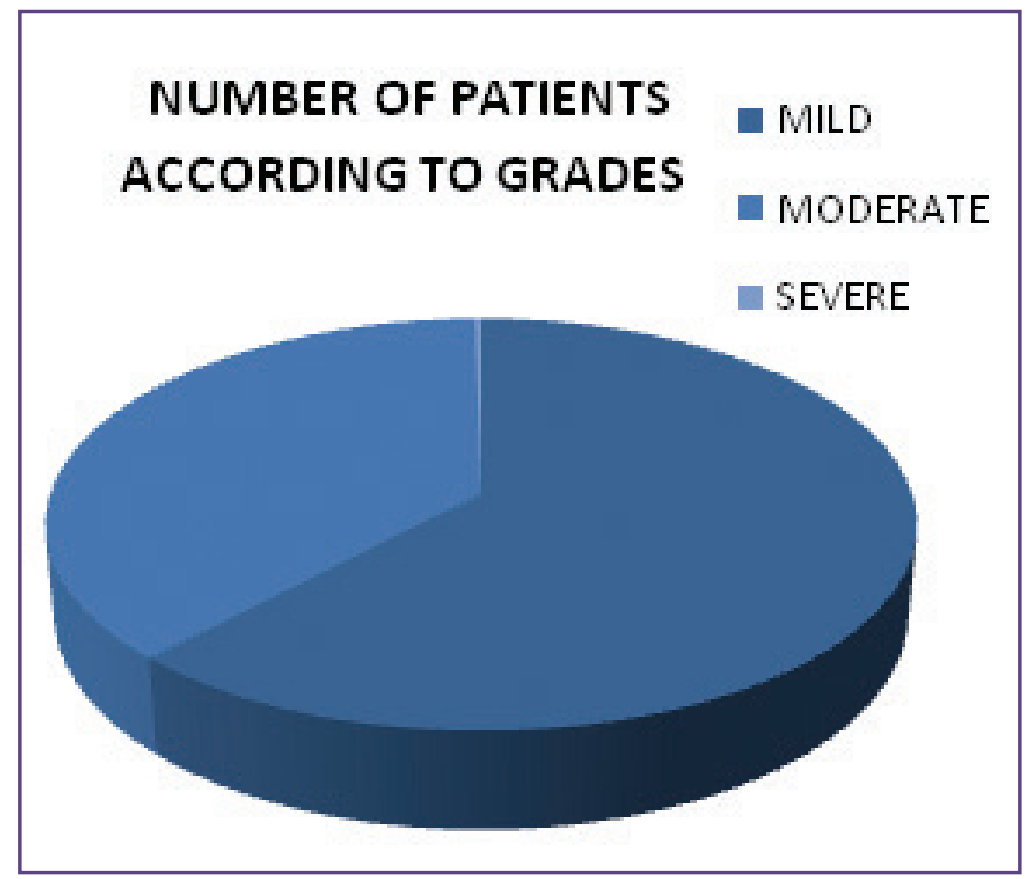

Graph 2: Grading of eosinophilia.

Table 1: Etiological distribution of eosinophilia.

\begin{tabular}{|c|c|c|c|}
\hline DIAGNOSIS & NUMBER OF PATIENTS & MALES & FEMALES \\
\hline Allergy/atopy/asthma & 2513 & 1908 & 605 \\
\hline $\begin{array}{l}\text { Intestinal helminthes } \\
\text { Roundworm (Ascaris lumbricoides) } \\
\text { Hookworm (Ancyclostome duodenale) } \\
\text { Tapeworm (Cestodes) } \\
\text { Hydatid cyst (Ecchinococcus granulosus) } \\
\text { Filariasis (Wucheria bancrofti) }\end{array}$ & $\begin{array}{c}342 \\
02 \\
05 \\
13 \\
04 \\
04\end{array}$ & $\begin{array}{l}178 \\
00 \\
00 \\
09 \\
03 \\
04\end{array}$ & $\begin{array}{l}164 \\
02 \\
05 \\
04 \\
01 \\
00\end{array}$ \\
\hline $\begin{array}{l}\text { Protozoa } \\
\text { Malaria } \\
\text { Leishmaniasis }\end{array}$ & $\begin{array}{l}04 \\
01\end{array}$ & $\begin{array}{l}03 \\
00\end{array}$ & $\begin{array}{l}01 \\
01\end{array}$ \\
\hline $\begin{array}{l}\text { Nasal polyp } \\
\text { Nasal polyp with fungus }\end{array}$ & $\begin{array}{c}107 \\
31\end{array}$ & $\begin{array}{l}79 \\
24\end{array}$ & $\begin{array}{l}28 \\
07\end{array}$ \\
\hline $\begin{array}{l}\text { Skin- Urticaria } \\
\text { Pemphigus } \\
\text { Dermatitis herpetiformis } \\
\text { Scabies } \\
\text { Leprosy } \\
\text { Lupus erythmatosis }\end{array}$ & $\begin{array}{l}87 \\
02 \\
05 \\
02 \\
06 \\
01\end{array}$ & $\begin{array}{l}34 \\
00 \\
00 \\
00 \\
05 \\
00\end{array}$ & $\begin{array}{l}53 \\
02 \\
05 \\
02 \\
01 \\
01\end{array}$ \\
\hline Drugs & 5 & 03 & 02 \\
\hline Gastroenteritis & 46 & 31 & 15 \\
\hline Hodgkins lymphoma & 4 & 04 & 0 \\
\hline Non hematological malignancy & 10 & 02 & 08 \\
\hline Hypereosinophilic syndrome & 03 & 03 & 00 \\
\hline Idiopathic & 245 & 161 & 84 \\
\hline TOTAL & & 2451 & 991 \\
\hline
\end{tabular}




\section{Discussion}

Eosinophilia was detected in about $10 \%$ of the population who visited the hospital. The disparity in the incidence in males and females is probably due to the fact that the overall number of female patients visiting the hospital is low as compared to males. Eosinophilia was seen in patients of all age groups. Many patients came with chief complaints associated with peripheral blood eosinophilia. In others it was an incidental finding, however with careful history and diagnostic work up, a definite cause could be assigned. The patients were treated for the cause and on follow-up showed down trending of eosinophil count. ${ }^{[2]}$

Eosinophilia in the bloodstream can be diagnosed by a simple blood test. If problem exists in body tissues then diagnoses will involve examination of the relevant tissue. A thorough patient history is the most important part of the evaluation for blood eosinophilia, and it should guide the extent and type of laboratory tests performed. ${ }^{[4,7,14]} \mathrm{We}$ also followed this dictum and our findings corroborated with numerous other authors. The initial focus is on signs and symptoms related to allergy and atopy. Most frequent complains of patient are skin rashes, itching, cough, sneezing, rhinitis, wheezing dyspnoea, redness and watery eyes. A recent or current history of drugs ingestion or medication may be important in some cases. ${ }^{[3,4]}$

A stool test should be performed to look for ova and larvae of intestinal worms (ascaris, schistosoma, ancylostoma, cestodes, fasciola, strongyloides). Next, depending on the native region of inhabitation, the following tests and procedures should be performed: urine sediment tests (schistosoma), blood concentration tests (filaria) and serology (strongyloides, filaria, trichinosis, visceral larva migrans, schistosomiasis). Radiological investigation can be done for diagnosis of various parasites, for instance $\mathrm{X}$-ray chest (paragonimiasis, ascariasis), CT scan (echinococcus, cysticercosis) etc. Gastric or small bowel or colon biopsy, removal of sinonasal polyps or skin biopsy in our patients was done based on the chief complaints. In our study intestinal helminths were detected either by stool examination or by biopsy examination. ${ }^{[7,9,11]}$

Fungal infection was seen associated with formation of nasal polyps. However, in our study fungal hyphae was seen in only 31 out of 148 cases of nasal polyps. The results reported in the literature are also variable..$^{[8,10,12]}$

However, work-up beyond complete blood count and stool examination is recommended only if history dictates. Similarly, a good history and basic laboratory tests should be adequate to address the possibility of a noninfectious cause of secondary eosinophilia, and only in the presence of historical clues should more invasive and costly interventions be pursued. In all patients with severe eosinophilia, bone marrow examination with cytogenetics should be done to rule out primary eosinophilia. Finally, in addition to looking for the cause of eosinophilia, laboratory tests to assess possible eosinophilic tissue damage may be required and include echocardiography, chest radiography, pulmonary function tests, and, in the presence of symptoms, tissue biopsy.

In past couple of years, significant advancement has been made in understanding the mechanisms of eosinophil production, apoptosis, and how eosinophil immunology contributes to both host defenses against infections and to tissue damage within the host in cases of allergic and autoimmune diseases. The primary stimuli for eosinophil production are interleukin (IL)-5, IL-3, and the granulocyte-macrophage colony-stimulating factor (GM-CSF). Simultaneously these cytokines are also the primary signals inhibiting eosinophil programmed cell death. Thus, eosinophilia can be triggered through these eosinophilopoietic cytokines by increased eosinophil production, eosinophil longevity, or by a combination of these. ${ }^{[1,2,5]}$ In addition, an evolving number of chemotactic cytokines have been established as causing eosinophils to migrate from their site of production in the bone marrow into the blood and then into peripheral tissues. These chemokines include eotaxin-1, eotaxin-2, and RANTES (regulated on activation normal $\mathrm{T}$ cell expressed and secreted).

Eosinophils are the source of a large number of cytokines, including IL-2, IL-3, IL-4, IL-5, IL-7, IL-13, IL-16, tumor necrosis factor-alpha (TNF-alpha), transforming growth factor-beta (TGF-beta), and RANTES. In addition to these cytokines, eosinophils are a source of several cationic proteins like eosinophil cationic protein (ECP), eosinophil peroxidase (EPO), lysophospholipase, major basic protein (MBP) and eosinophil-derived neurotoxin (EDN), that also contribute to their immunologic responses. ${ }^{[5,12]}$

Secondary eosinophilia is a reactive phenomenon driven by eosinophilopoietic cytokine release by nonmyeloid cells. Eosinophilic differentiation occurs in the bone marrow from myeloid progenitors through the actions of GM-CSF, IL-3, and IL-5. Mature eosinophils are released into the bloodstream where they migrate quickly to peripheral tissues of the bronchial and gastrointestinal mucosa and skin. Dysregulated production of these cytokines by various cell populations account for secondary hypereosinophilia seen in nonmyeloid malignancies (eg, Hodgkin lymphoma, adenocarcinomas of the stomach, colon, lung and uterus; allergic reactions, parasitic infections, and other conditions. Primary eosinophilias include increased count for longer 
than six months, without evidence of reactive cause and cytogenetic or molecular evidence of clonality. ${ }^{[5,7,14]}$

Finally, idiopathic hypereosinophilic syndrome (HES) is the diagnosis of exclusion in patients with marked prolonged $(>6 \mathrm{mo})$ eosinophilia with multiple organ involvement but without identifiable cytogenetic or molecular abnormalities. Organ damage occurs from release of the contents of eosinophilic granules. Some of these cases transform into identifiable entities. ${ }^{[13,14]}$

\section{Conclusion}

Eosinophilia appears to be a common occurrence in the in the rural population around our hospital. The most common etiologies were due to parasitic, protozoal or fungal infestations and infections. Allergy related problem also constituted a significant health problem in the local population. In a significant proportion of patients a definite etiology of eosinophilia could not be zeroed upon. Individuals of all ages can be affected by eosinophilia. Children and young adults usually had mild eosinophilia. Severe eosinophilia was seen in middle aged or elderly patients. The evaluation of unexplained eosinophilia in an asymptomatic individual is a challenging problem that requires knowledge about a wide variety of potential pathogens. Nevertheless, the prevention of morbidity by the diagnosis and prompt treatment of parasitic helminth infection is also an important task in these patients.

\section{References}

1. Valent P, Klion AD, Rosenwasser LJ et al. ICON: Eosinophil Disorders. The World Allergy Organization Journal 2012;5(12):174-181.

2. Nutman TB. Asymptomatic peripheral blood eosinophilia redux: Common parasitic infections presenting frequently in refugees and immigrants. Clin Infect Dis 2006;42(3): 368-369.
3. Webb JKG.. Etiology of tropical eosinophilia. Indian Journal of Tuberculosis 1961;8 (3):95-98.

4. Udwadia FE. Tropical eosinophilia. In:Herzog H. Pulmonary eosinophilia: Progress in respiration research. 7th ed. Basel. Karger 1975:35-155.

5. Turnbull LW, Evans DP, Kay AB: Human eosinophils, acidic tetrapeptides(ECF-A) and histamine. Interactions in vitro and in vivo. Immunology 1977;32:57-68.

6. Samuel AM, Udwadia FE, Parab PB et al. Cell mediated and humoral immune response in tropical eosinophilia. Indian Journal of Medical Research 1978;68:444-449.

7. Dacie YV, Lewis SM. Basic hematologic techniques. Practical Hematology, 7th ed. Edinburg: Churchill Livingstone 1991:37-68.

8. Epstein FH. Eosinophilia. N Engl J Med 1998;338:15921600.

9. Knopp S, Mgeni AF, Khamis IS et al. Diagnosis of soiltransmitted helminths in the era of preventive chemotherapy: effect of multiple stool sampling and use of different diagnostic techniques. PLoS Negl Trop Dis 2008;2(11):331.

10. Glass D, Amedee RG. Allergic fungal rhinosinusitis: a review. Ochsner J 2011; 11(3):271-275.

11. Mori A, Enweluzo C, Grier D et al. Badireddy M. Eosinophilic gastroenteritis: Review of a rare and treatable disease of the gastrointestinal tract. Case Reports in Gastroenterology 2013;7(2):293-298.

12. Mullerpattan JB, Udwadia ZF, Udwadia FE. Tropical pulmonary eosinophilia - A review. The Indian Journal of Medical Research 2013;138(3):295-302.

13. Haider S, Farhangi M. Hypereosinophilic Syndrome. Indian Journal of Practicing Doctors 2005;2(3):

14. Weller PF. Eosinophilic syndromes. In: Goldman L, Bennett JC, eds. Cecil Textbook of Medicine., 25th Ed. Philadelphia: W.B. Saunders 2000:1151-1154

*Corresponding author:

Dr Rimpi Bansal, 320, Sector-32-A, Chandigarh- 160031, India

Phone: +91 91-9915025927

Email: rimpijatinsarin@yahoo.com

Date of Submission : 23.08.2016

Date of Acceptance : 25.11.2016

Financial or other Competing Interests: None.
Date of Publication : 04.02.2017 